\title{
A Comparative Study on Three Pioneer Methods for the Square Roots
}

\author{
Krishna Kanta Parajuli \\ Department of Mathematics, Valmeeki Campus, Nepal Sanskrit University, Nepal \\ Email: kknmparajuli@gmail.com
}

\begin{abstract}
During the classical period, the South Asian region had an illustrious history of mathematics, and it was regarded as fertile ground for the birth of pioneer mathematicians that produced a wide range of mathematical ideas and creations that made significant contributions. Among them, three creative personalities Bhaskaracarya, Gopal Pande and Bharati Krishna Tirthaji and their specific methods to find square roots are focused on this study. The analytical study of their methods is expressing in comparison with similarities, variety and simplicity.

Each of the three mathematical treatise has its own formula for calculating the square roots. The Lilavati seems to have some effect upon the Vedic and Pande's systems. In spite of having influenced by Lilavati, Gopal Pande disagreed on the problems regarding square roots and cube roots. To prove his point, Gopal Pande used the unitary method against the method described in Bhaskaracarya's famous book Lilavati. In the case of practicality and simplicity, the Vedic method is more practical, interesting and simpler to understand for the mathematics learners in comparison to the other two methods.
\end{abstract}

Keywords: Square Root, Lilavati, Pande's method, Vedic Mathematics.

\section{Introduction}

In mathematics, a square root of a number $\mathrm{n}$ is a number $m$ such that $m^{2}=n$. In other words, a square root of a number is another number which, when multiplied by itself, produces the first number. A positive (real) number has two real square roots, a negative number two imaginary square root. The positive square root of a positive number $\mathrm{n}$ is denoted by $\sqrt{n}$ [8]. There are two methods taught in our present-day classroom in school level by conventional approach i.e., method of factors and method of division. Both the methods are lengthy and time consuming by conventional approach. Therefore, extracting the square root of a number is considered a tedious job for school level students without using calculator.

The estimation of square roots has a long tradition dating back to Babylonian civilization. Babylonian collection clay tablet was created around $1800 \mathrm{BC}$ to $1600 \mathrm{BC}$ by showing $\sqrt{2}=1.414213 \ldots \ldots$ [17] Egyptian extracted square roots by an inverse proportion method in $1650 \mathrm{BC}$ [2],[4] . In ancient India, the knowledge of square roots was at least as old as Sulbha Sutras, dated around $800 \mathrm{BC}$ to $500 \mathrm{BC}[1],[5]$. Aryabhata, in Aryabhatiya has given a method for finding the square root of the number [5]. It was known to the ancient Greeks that the square roots of the positive integers that are not perfect squares are always irrational number [5]. The square root of 2 is assumed to date back earlier to Pythagorians [5]. In china, the square root is approximated by using "excess and deficiency" method in between $202 \mathrm{BC}$ to 186 BC [7]. According to Jeffrey A. Oaks (1964), Arabs used square root at the end of twelfth century[11]. According to historian of mathematician D.E. Smith (1922 - 1974), Aryabhata's method for finding square roots was first introduced in Europe in 1546 [5].

Apart from the above-mentioned mathematical society, mathematicians who used classical procedures have made significant contributions to the discovery of square roots. Among them, the South Asian region is regarded as fertile ground for the birth of pioneer mathematicians who produced a wide range of mathematical concepts and inventions [14]. This article mainly focused on three South Asian 
mathematicians who significantly differed or provided the elementary structure for finding the square root. Here, only the comparison of methods of Bhaskaracarya, Gopal Pande, and Tirthaji has been designated for this study, and a neutral analysis with relations, comparison, and contrast for their respective methods to find the square roots has been performed.

\section{Nature of the Number and its Square Roots}

Before studying the various methods to find the square root of a number, we should understand the following fundamental rules, natures and characters of the numbers and its square roots. The nature of the square and square roots of the first 20 natural numbers $(\mathrm{N})$ as defined in table No.1 should be studied.

Table No. 1

\begin{tabular}{|l|l|l|l|l|l|l|l|l|l|l|l|l|l|l|l|l|l|l|l|l|}
\hline $\begin{array}{l}\text { Square } \\
\text { Roots (N) }\end{array}$ & 1 & 2 & 3 & 4 & 5 & 6 & 7 & 8 & 9 & $\mathbf{1 0}$ & 11 & 12 & 13 & 14 & 15 & 16 & 17 & 18 & 19 & 20 \\
\hline $\mathrm{N}^{2}$ & 1 & 4 & 9 & 16 & 25 & 36 & 47 & 64 & 81 & $\mathbf{1 0 0}$ & 121 & 144 & 169 & 196 & 225 & 256 & 289 & 324 & 361 & 400 \\
\hline $\begin{array}{l}\text { Last digits } \\
\text { of } \mathrm{N}^{2}\end{array}$ & 1 & 4 & 9 & 6 & 5 & 6 & 9 & 4 & 1 & $\mathbf{0}$ & 1 & 4 & 9 & 6 & 5 & 6 & 9 & 4 & 1 & 0 \\
\hline
\end{tabular}

Apart from the above table, let us look at the following nearest square root table that will help us to find the square root of a number instantly.

Table No. 2

\begin{tabular}{|l|c|c|c|c|c|c|c|c|c|}
\hline Numbers & $1-3$ & $4-8$ & $9-15$ & $16-24$ & $25-35$ & $36-48$ & $49-63$ & $64-80$ & $81-99$ \\
\hline $\begin{array}{l}\text { Nearest greatest integer } \\
\text { of square roots }\end{array}$ & 1 & 2 & 3 & 4 & 5 & 6 & 7 & 8 & 9 \\
\hline
\end{tabular}

Table No.1 demonstrates only from the natural number 1 to 20 . The pattern of the relations of the squares and the square roots broadened similarly. From the table, it can be concluded that,

(i) Every perfect square end either of the numbers: $0,1,4,5,6$ or 9.

(ii) A square ending in 1 must have 1 or 9 as the last digit of the square root. A square ending in 4 must have 2 or 8 as the last digit of the square root. A square ending in 6 must have 4 or 6 as the last digit of the square root. A square ending in 5 must have 5 as the last digit of the square root. A square ending in 9 must have 3 or 7 as the last digit of the square root. A square ending in 0 must have 0 as the last digit of the square root.

(iii) If the number has $\mathrm{n}$-digits then the number of digits in square roots $=$ $\frac{n}{2}$ digits, if $n$ is even.

$\frac{n+1}{2}$ digits, if $n$ is odd.

(iv) A number cannot be a perfect square in the following circumstances[21],

- if it ends in $2,3,7$ or 8 ;

- if it terminates in an odd number of zeros;

- $\quad$ if its last digit is 6 but its penultimate (2nd last) digit is even;

- $\quad$ if its last digit is not 6 but its penultimate (2nd last) digit is odd;

- $\quad$ if, even though the number be even, its last two digits (taken together) are not divisible by 4 .

\section{Three Pioneer Mathematicians and Analysis of Their Methods}

Many mathematicians played an important role in the creation of mathematics' glorious history. Three mathematicians stand out among them: Bhascaracharya-II, Gopal Pande, and Bharati Krishna Tirthaji, whose mathematics are more applicable to this article.

\subsection{Lilavati of Bhaskaracarya}

Bhaskaracarya or Bhaskara-II (1114 -1193) was the famous leading Mathematician, Poet, and Astronomer of ancient Indian during the twelfth century. Bhaskaracarya wrote his Siddhantasiromani when he was 36. It consists of four parts: Lilavati, Algebra, Planetary motion, and Astronomy [12],[15],[16]. The first part Lilavati mainly deals with Arithmetic but also contains portions of Geometry, Trigonometry and Algebra. Bhaskaracarya's Lilavati has been used as a text-book for the last 
eight hundred years in many south Asian countries and is still in practice in many Indian provinces[15],[16].

In his famous book Lilavati, Bhaskaracarya defined the method and procedures for obtaining the square root of a number in Sanskrit stanza as follows [16].

$$
\begin{aligned}
& \text { त्यक्त्वान्त्याद्विषमात् कृति द्विगुणयेन्मूलं समे तद्धृते } \\
& \text { त्यक्त्वा लब्धकृति तदाद्यविषमाल्लब्धं द्विनिघ्नं न्यसेत् । } \\
& \text { पंक्त्या पंक्तिहत्ते समेऽन्त्यविषमात्त्यक्त्वाप्तवर्गं फलम् } \\
& \text { पंक्त्यां तद्द्विगुणं न्यसेदिति मुहुः पंक्तेर्दलं स्यात्पदम् ॥ }
\end{aligned}
$$

(Tyakttwantadwishmaat kritim dwigunenmulam same taddhrite

Tyakttwa labdhakritim tadaddhyawishamallbdham dinighanam neyset

Panktywa panktiwrite sameanttyawish hamattyakttwaptabargam falam

Panktyam taddwigunam neysediti muhumha pankterdalam syatpadam.)

Meaning: Starting at the unit's location, alternately mark vertical and horizontal bars above the digits so that the given number is divided into two-digit groups, with the exception of the extreme left group. The extreme left group will have either one or two digits, with a vertical bar on the top or right digit, as appropriate [16]. Subtract the largest possible square of $a_{1}$ from the group on the extreme left. Then write $2 a_{1}$ in the adjacent column; this is known as pankti (row). With a horizontal bar to the right of the number obtained from the above subtraction, write the digit from the next group. Now divide the result by $2 a_{1}$; the quotient $a_{2}$ should not be greater than 9. After moving $2 a_{1}$ one position to the right, write $2 a_{2}$ below $2 a_{1}$ and add. The second pankti is the result. Subtract the square of the second quotient $a_{2}$ from the remainder obtained by writing the next digit to the right of it. Write the next digit to the right of the remainder and divide it by the second pankti. This yields the appropriate square root's third digit. After moving the second pankti one position to the right, double the third digit of the square root should be inserted. The third pankti is the result. Then, to the right of the remainder, write the next digit of the specified number and subtract the square of the third digit of the square root. Repeat the procedure. The requisite square root is obtained as a result [16].

\subsubsection{Bhaskaracarya's Method to Find Square Roots}

To gain a better understanding of Bhaskaracarya's process for finding square roots in his book Lilavati, let's look at an example of finding the square root of 20736.

Rule of Lilavati to find Square root by illustrating as below,

- Group the given number 20736 as 20736 in three groups.

- The extreme left group contains only one-digit number i.e., 2.

- $1^{2}<2<2^{2}$. Therefore, the first number of square roots is 1 .

- Deduct $1^{2}$ from 2 i.e., 1 . Then $2 \times 1$ (first number of square root) $=2$ is the first pankti (row).

- Next dividend become 10. Divide this number by 2 (pankti number), which gives $\mathrm{Q}=5$ and $\mathrm{R}=$ 0 . Being 0 in remainder, it should be revised the quotient and remainder. Therefore, revised $Q=4$ and $\mathrm{R}=2$. It should also be noted that the quotient shouldn't be more than 9 .

- Write 7 to the right of the remainder 2 to get 27 .

- From 27 subtract $4^{2}$ to get 11 .

- Write 3 of the given number to the right of 11 to get 113 .

- After arranging and placing the numbers as shown in the table, new dividend and pankti numbers will be obtained by adding.

- 28 would be the second pankti. Divide the new dividend 113 by second pankti then $\mathrm{Q}=4 \& \mathrm{R}=01$.

- Write the last digit 6 of the given number to the right of 01 to get 16 .

- From this 16 , subtract $4^{2}$ to get the remainder 0 .

- 144 is the required square root from root column, which is always half of the third pankti. 
Table No. 3

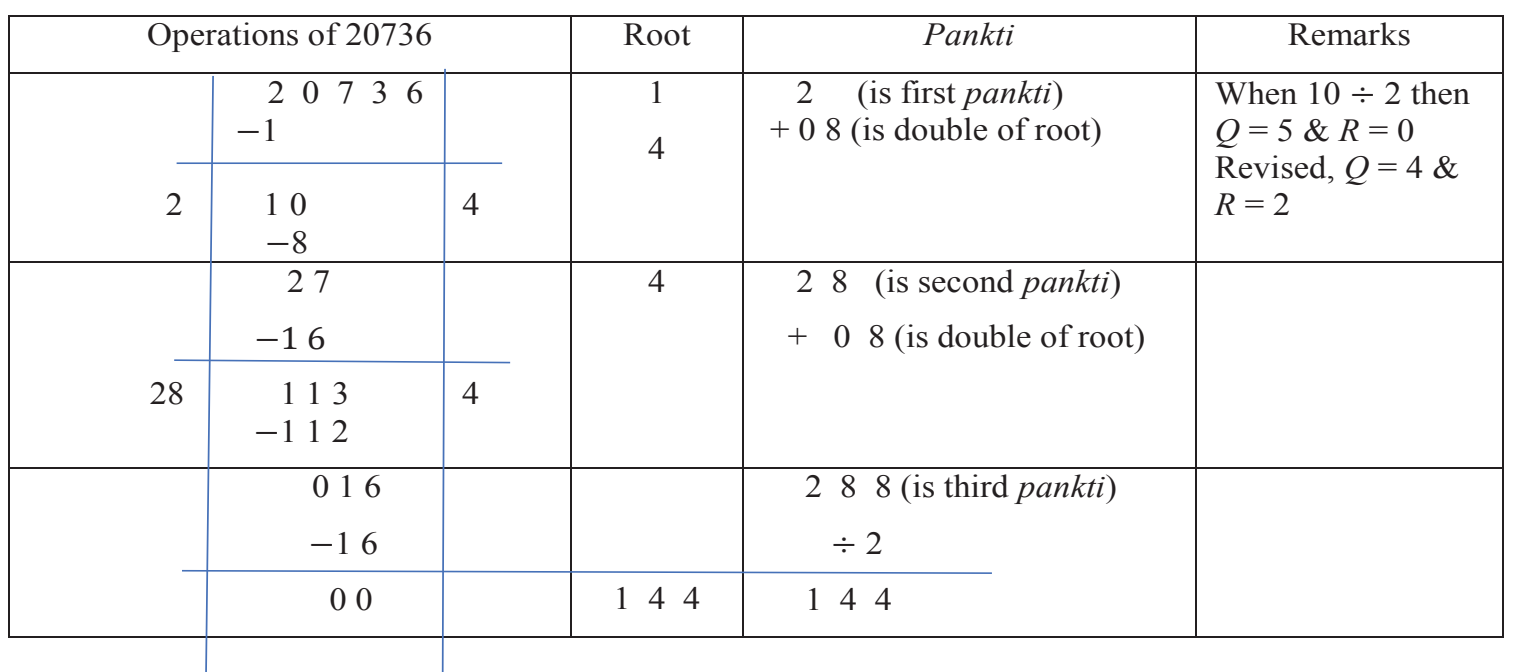

\subsection{Gopal Pande and His Method}

Gopal Pandey (1847-1920), the first Nepali mathematician, was the first to write mathematics. In the Nepali language, he published Wyaktachandrika (व्यक्तचन्द्रिका) in four editions between 1883 and 1914 [12],[14]. Among them his third edition was written in Hindi [10],[12],[15]. He wrote Wyaktachandrika by reorganizing Lilavati principles, as well as ideas from his teacher Bapudev Shastri and other texts. Despite the fact that Pande's work was mostly based on Bhaskaracarya's Lilavati [12],[15]. His book was considered as the best book for teaching mathematics at that time [9]. Nepal published the first Nepali calendar (Panchanga) in 1884. Pande discovered an error in the forecasting of the Lunar eclipse that year in this calendar. After much deliberation, it was determined that Gopal Pande's conclusion was correct. He was awarded the title of Royal Astrologer in recognition of his achievements.[9],[10],[15].

As a neighboring country with similar cultural and social-behavioral characteristics, Nepal and India had a direct impact on the teaching-learning process. In every field of education, the majority of Nepali scholars collaborated with Indian scholars and exchanged ideas. Nepal purchased all of its mathematical textbooks from India, which were written in either Sanskrit or Hindi. Moreover, India was the main source of Nepali scholars in every aspect of the subjects at that time [12].

The article discusses how the Pande's claims about the method for finding square roots are accurate. Nepali mathematician Gopal Pande disagrees with the Bhaskaracarya's verse when it comes to finding the square and cube roots of a number. Gopal Pande is credited with making a significant contribution to Nepali mathematics with this modern approach.

The unitary method or rule of three cannot be used to find the square and cube roots, according to Bhaskaracarya's book Siddhantasiromani. In this regard, he expressed his thoughts in Sanskrit as follows: [12]

$$
\begin{aligned}
& \text { वर्गं वर्गपदं घनं घनपदं संत्यज्य यद् गण्यते } \\
& \text { तत् त्रैराशिकमेव भेदबहुलं नान्यत् ततो विद्यते । }
\end{aligned}
$$

(सिद्धान्तशिरोमणि प्रश्नाध्याय)

(Vargam vargapadam ghanam ghanapadam samtyajya yad ganyate

Tat trairashikmewa bhedabahulam nanyat tatwo vidhyate.)

\section{- Siddhanta Siromani Prasnadhyaya}

Meaning: The above Sanskrit verse means that, with the exception of finding squares, square roots, cubes, and cube roots, any mathematical problem can be solved using the rule of three or the unitary method. Professor Naya Raj Pant (1913 - 2002) demonstrated Pande's mathematical contribution with groundbreaking techniques in his book Pandit Gopal Pande and His Method of Getting Cube Root ( पण्डित गोपाल पाण्डे र उनको घनमूल ल्याउने रीति ), published in 1980. The rule of three, according to Gopal Pande, can be used to find squares, square roots, cubes, and cube roots of a positive integer [12],[14]. 


\subsubsection{Pande's Methods to Find Square Roots [12]}

According to Acharya in expressing the views for calculation of the cube roots by Gopal Pande's methods, he mentioned that, there were different links to classical to modern mathematics that differed the method in mathematics operating system among the persons, communities, civilizations etc, $[1]$. He also focused the rule of three for calculating cube roots as Pande's method in his book Vyaktachandrika that differed to Bhaskaracarya's view[3].

Gopal Pandey believed that by using the unitary method or the rule of three and treating differently, the correct result would be obtained. It is easier to grasp the concepts of Pande's method for finding square roots by using the example of finding the square root of the number 5776 . He achieved this by expressing his ideas using the following strategies in a step-by-step manner:

- Place dots above the first digit (Unit digit) then above every third digit (Hundredth place) then above fifth digit (Ten thousandth place) and so on from the right of the given number which has to be found the square root.

- The number of dots is equivalent to the digits of required square roots.

- For the number 5776, it will have 2-digits square root being two dots $5 \dot{7} 7 \dot{6}$.

- From the left of the number, first it will be taken square root of 57 which is greater than 7 but less than 8 . Then it will be conformed that the required square root will be greater than 70 and less than 80 . Therefore, for difference in square root by $80-70=10$, the difference of their squares is $80^{2}-70^{2}=1500$. That is, when the difference between two squares is 1500 then the difference between two square roots would be 10 .

- Now the number $57-49=8$ with the number 76 (last two number) become 876 .

- Hence in this case, Gopal Pandey uses the unitary method or rule of three as:

\begin{tabular}{|c|c|c|l|}
\hline Difference of squares & Difference of sq. roots & Square root & \multicolumn{1}{|c|}{ Remarks } \\
\hline 1500 & 10 & $\frac{10}{1500} \times 876=5.84$ & $\begin{array}{l}\text { Next number of required } \\
\text { square root }=5+1=6\end{array}$ \\
\hline
\end{tabular}

Therefore, square root of $5776=76$.

Hence, Gopal Pande's idea for finding square roots by unitary method in each step of operation can be formulated as follows:

Each number of the required square roots from the left can be obtained (for each step) by using the formula $=\frac{\text { The number formed by }\left(x-a^{2}\right) \text { with the number of next two digits of given dividend }}{10(2 a+1)}+1$,

where $x$ and $a$ are varying in each step and hence varying the square roots.

$x=$ The number (taken from left side of the given dividend) to be taken at that time. For first step, $x=57$, for second step, $x=\left(57-7^{2}=8\right)$ with the number 76 (which is the next two digits of given number from left side) becomes 876 .

$a=$ digit of square root of previous step.

Remarks: $a^{2}=$ Maximum square to be taken from left. It should be noted that $\mathrm{x}$ must be greater than $a^{2}$. If there occurred negative, there must readjust by deducting in the value of a (deducting by an adjustable number from $a$ ).

\subsection{Bharati Krishna Tirthaji}

Jagadguru Sankaracharya Sri Bharti Krishna Tirthaji (1884 -1960), a well-known Indian cultural figure, was a glorious and divine person. He is famous for formulating and reconstructing Vedic Mathematics from the Sanskrit text Veda. Tirthaji formulated and reconstructed Vedic Mathematics between 1911 and 1918, but it wasn't published until 1965, after his death in 1960 [15],[18],[19],[20].

\subsubsection{Square Roots in Vedic Mathematics}

Getting the square root of a number is a time-consuming task. In our current classrooms, we are taught two methods: the method of factors and the method of division. By using the traditional approach, both 
approaches are lengthy and time consuming. The Vedic Sutra, on the other hand, teaches us how to measure square roots of any given number in a straightforward manner.

Bharati Krishna Tirthaji's Vedic Mathematics has 16 formulas and a similar number of sub-formulas that cover most of the mathematical fields, such as arithmetic, algebra, geometry, trigonometry, calculus, and so on, and effectively solve their problems [14],[18],[19]. Vedic mathematics consists of two methods to find square roots, they are Vilokanam (i.e., By mere observation) and Dwanda Yoga (i.e., Duplex Combination). Both the methods are included in the list of sub-formulae of Vedic Mathematics[19],[20]. The first method Vilokanam was discussed in the article entitled "Square Roots in Vedic Mathematics" by the same author [13]. In this article, the study is focused on Dwanda Yoga.

\subsubsection{Square Roots by Dwanda Yoga in Vedic Mathematics}

Out of Vedic sub-sutras, Dwanda Yoga is unique one. It is also working as duplex combination. This method is applicable to all the numbers, whether the given numbers is perfect square number or imperfect square number. Specially, the formula is used to find the squaring the numbers. When we use the duplex of the number by $\mathrm{D}$, then duplex of one-digit number ' $a$ ' ' is written as $D(a)$ and it is defined by $D(a)=a^{2}$. Duplex of two-digits numbers $a$ and $b$ is written as $D(a b)$ and defined by $D(a b)=2 a b$. Duplex of threedigits numbers $a, b$, and $c$ is written as $D(a b c)=2 a c+b^{2}$. Duplex of four-digits numbers a, b, c and d is written as $D(a b c d)$ and defined by $D(a b c d)=2 a d+2 b c$. Similarly, for more-digits numbers [19],[21].

\section{Rules of Vedic Method [6],[18],[19],[21]}

- Make the group of two-digits at a time from right to left. Left most part (LP) may contain one or two-digits. If there are odd numbers of digits, then the left most group will contain one-digit only.

- The number of groups of the given number determines the number of digits in the square root i.e., the square root of a $\mathrm{n}$-digits number will contain $\frac{n}{2}$ or $\frac{n+1}{2}$ digits.

- The divisor is double the first digit of the square root.

- But, in case of pure decimals the number of digits in the square is always double that in the square root.

- The duplex of the second digit onwards is subtracted from the new divisor in each step.

- If the duplex is subtracted from the dividend and we get a negative number, we use an alternative remainder to calculate the next dividend.

- Our division is complete, if we get a zero for both the quotient and remainder, otherwise we have an irrational answer.

- We must care about the above-mentioned tables, ideas and concepts related to square roots.

Working procedure of the Duplex method can be illustrated by taking an example. The working of the duplex method is as simple as straight division. For this, let us take an example of 5625.

A step-by-step illustration can be shown as follows

- Group the number 5625 as 56 and 25 i.e., two groups.

- Set-up a table as shown below

\begin{tabular}{|c|c|c|}
\hline 14 (Double of first-digit of sq. root) & 56 & 72 \\
\hline Quotient (Sq. root) & 7 & 5 \\
\hline
\end{tabular}

- Since $7^{2}<56<8^{2}$, the first digit of the square root in quotient row is 7 . Set-up the divisor as double of the quotient i.e., $2 \times 7=14$.

- $\quad$ Remainder $=56-7^{2}$ (i.e., Duplex of 7) $=7$. Put this remainder in front of next dividend digit i.e., 72 .

- Divide 72 by 14 , where quotient $=5$ and remainder $=2$.

- Next dividend becomes 25 , then net dividend is $25-$ Duplex of $5=25-5^{2}=0$.

- Since no more digits are left. Therefore, square root of 5625 is 75.

To be more cleared about the square root, it will be better to take another example such as 20736 .

- Group the given number 20736 as $207 \quad 36$

- Set-up a table as below 


\begin{tabular}{|c|c|cc|}
\hline 2 (Double of first-digit of sq. root) & 2 & ${ }_{1} 0_{2}{ }_{2}$ & ${ }_{3} 3{ }_{1} 6$ \\
\hline Quotient (Sq. root) & 1 & 4 & 4 \\
\hline
\end{tabular}

- Since $1^{2}<2<2^{2}$. Therefore, the first digit of the square root is 1 .

- $\quad$ Set-up the divisor as the double of the quotient i.e., $2 \times 1=2$.

- $\quad$ Remainder $=2-1^{2}$ (i.e., Duplex of 1$)=1$. Put this remainder in front of next dividend digit i.e., 10 .

- Net dividend $=10$ (Divide 10 by 2 , where quotient $=5$ and remainder $=0$. Since the remainder cannot be taken as 0 until the whole operation is completed. Therefore, the quotient should be revised. Hence the quotient $=4$ and remainder $=2$.

- Next dividend become 27, then net dividend is $27-$ Duplex of $4=27-4^{2}=11$.

- $\quad$ Net dividend $=11$. When 11 is divide by 2 then $Q=5$ and $R=1$.

- Next dividend $=13-D(45)=13-2 \times 4 \times 5=-27$ which is less than zero. Since the dividend cannot be taken as negative. Therefore, quotient and remainder should be revised

- $\quad$ by $\mathrm{Q}=4$ and $\mathrm{R}=3$. Now the new dividend is 33 and net dividend $=33-\mathrm{D}(44)=33-2 \times 4 \times 4=1$.

- New net dividend $=1$. When 1 is divided by 2 then $Q=0$ and $R=1$.

- $\quad$ Next dividend $=16-D(440)=16-2 \times 4 \times 0-4^{2}=0$.

- Since no more digits are left. Therefore, square root of 20736 is 144.

\section{Findings}

- In all procedures, the first digit of the square root can be found by observing the first part of the number (it is either one-digit or two-digits numbers)

- In all the procedure, there should be remembered the square and square root table from 1 to 10 , the provided facts and its left-most pair with the nearest square roots to determine the required square roots.

- In all procedures, square roots of imperfect square numbers can be extracted.

- In all procedures, if the number has n-digits then the square roots will have $=\left\{\begin{array}{l}\frac{n}{2} \text { digits, if } n \text { is even. } \\ \frac{n+1}{2} \text { digits, if } n \text { is odd. }\end{array}\right.$

- Pande's idea for finding square roots by unitary method in each step of operation can be formulated as follows:

each number of the required square roots from the left can be obtained by using the formula

$$
=\frac{\text { The number formed by }\left(x-a^{2}\right) \text { with the number of next two digits of given dividend }}{10(2 a+1)}+1 \text {, }
$$

where $x$ and $a$ are varying in each step and hence varying the square roots.

$x=$ The number (taken from left side of the given dividend) to be taken at that time.

$a=$ digit of square root of previous step.

- In Pande's procedure, the digit of square root is obtained by managing the difference of two consecutive numbers multiplied by 10 and its corresponding squares using unitary method.

- In Pande's method, the numbers which are not a perfect square can be obtained from the square roots of a decimal number by introducing two zeros to the remainder obtained in the previous steps and proceed as above.

- Being using unitary method, the procedure of Pande's idea is unique one.

- In three procedures, the structural format tables are very different from one another.

- Bhaskaracarya and Tirthaji take one-digit at a time whereas Pande take two-digits at a time in their procedures.

- The remarkable term in Lilavati is Pankti, Duplex has the significant role in Vedic Mathematics whereas Unitary Method has valuable role for Pande's procedures. 


\section{Conclusions}

It is quite clear that Lilavati of Bhaskaracarya is the pioneer book in the history of mathematics. The mathematical tools developed after the upsurge of Lilavati of Bhaskaracarya directly or indirectly were certain to affect the later developed procedures. Minute detections of the history attests that Lilavati's and Pande's ideas are interrelated in some major aspects except to find the square, square root, cube and cube root of the numbers. Pande expressed his techniques innovatively and differently by breaking the verse of Bhaskaracarya.

After the period of Pande, another emerging mathematician Bharati Krishna Tirthaji known as the father of Vedic mathematics in India developed an independent and constructive method. His idea of determining square roots is more or less influenced by the previously developed methods from Lilavati. And it has been evident that the similarity in few steps to find square root of the numbers in Lilavati and Vedic system is comparable and Vedic mathematics is quite related to the Lilavati. The word 'Pankti' in Lilavati and the word 'Duplex' in Vedic Mathematics are more or less similar. Meanwhile, the direct interrelation between the procedures to find square roots of a number in Lilavati and the Pande's system is not that prominent.

To measure the effectiveness of the new concepts and ideas, it is better to compare it with the conventional methods. In conventional system, student must require a calculator for their numerical calculation to find square root. The structural format table in Vedic Method is comparatively comfortable than others. The practice of Vedic Mathematics may be very fruitful for the teaching-learning process of basic mathematical operations without using a calculator.

\section{References}

[1] Acharya, E. R. (2016). Antiquity of Nepali Mathematics. American Research Journal of History and Culture, Vol. 2016: 1-10

[2] Acharya, E. R. (2021). Cretan Hieroglyphs Numerals: A Brief Information. Research \& Reviews: Journal of Social Sciences, 7(2): 2021.

[3] Acharya, E.R.(2015). Mathematics Hundred Years Before and Now. History Research, 3(3): 41 - 47.

[4] Anglin, W. S. (1974). Mathematics: A Concise History and Philosophy. New York: Springer.

[5] Bailey, D. H. and Borwein J. M. (2017). Ancient Indian Square Roots: An Exercise in Forensic PaleoMathematics. The American Mathematical Monthly, 119(8): 646-657.

[6] Chauthaiwale, S. and Kolluru, R.(2010). Enjoy Vedic Mathematics. Sri Sri Publication Bangalore, 1: 197 $-210$

[7] Dauben, J. W.(2007). Chinese Mathematics I. New Jersey: Princeton University Press.

[8] James and James (1988). Mathematics Dictionary. CBS Publishers \& Distributer, Delhi.

[9] Jha, K., Adhikari, P. and Pant, S. (2006). A History of Mathematical Sciences in Nepal. Kathmandu University Journal of Science, Engineering and Technology, 2(1): 1 - 6.

[10] Maskey, S. M. (2014). Mathematics in Nepal, Online.

[11] Oaks, J. A. (2012). Algebriac Symbolism in Medieval Arabic Algebra, Philosophica pp. 27-83

[12] Pant, N. R., Pandit Gopal Pande.(1980). Method to find cube roots. Nepal Rajakiya Praggya Pratisthan, Kathmandu, pp. 64 - 86.

[13] Parajuli, K. K.(2019). Square roots in Vedic mathematics. Mathematics Education Forum, 4(4): 64-71.

[14] Parajuli, K. K.(2021). Three classical methods to find the cube roots: A connective prospective on lilavati, Vedic and Pande's Procedures. Journal of Nepal Mathematical Society, 4(1):23-32

[15] Parajuli, K. K.(2021). Three Separate Methods for Squaring: A connective Prospective on Lilavati, Vedic and Trachtenberg. International Journal of Statistics and Applied Mathematics, 6(2): 43-47.

[16] Patwardhan, K. S., Naimpally S. and Singh S.(2015). Lilavati of Bhaskaracharya.Motilal Banarasidass Publishers, Delhi, pp. 23-25.

[17] Saggs, H. (1989). Civilization Before Greece and Rome, Yale University Press, p. 127.

[18] Singhal, V. (2014). Vedic mathematics for all ages. Motilal Banarsidass publishers Pvt Ltd, New Delhi.

[19] Thakur, R. K.(2016). Essential of Vedic mathematics, New Delhi: Rupa publications Pvt. Ltd..

[20] Tirthaji ,B. K. (2015). Vedic Mathematics, V. S. Agrawala, New Delhi: Motilal Banarasidass pvt. ltd., 17 th ed. 